\title{
THE GOOD, THE BAD, AND THE \#BESTOFISLAVISTA: COMMUNITY DATA GATHERING AND RESEARCH BY OUR YOUTH LEADERSHIP GROUP
}

\author{
BRANDON VILLALVA \\ St. George Youth Center
}

BRISEIDA MARTINEZ

St. George Youth Center
NATALIA RIOS

St. George Youth Center

FRANCESCA SEN

St. George Youth Center
VICTOR BALBUENA

St. George Youth Center

ODALIS PACHECO MENDEZ

St. George Youth Center

JASMINE MCBEATH

University of California Santa Barbara

\section{ABSTRACT}

In this article, we present our teen leadership group and projects. We describe our "I'm a Student, Too!" campaign and why it is important to raise awareness about Latino/a children and families that live in Isla Vista, California, which has the reputation of being a college town. We outline our group's mandate to create a better, safer, and healthier place where youth and families can grow up. We then describe how we collected data on people's opinions of Isla Vista over the past two years and how we shared this information at town halls, University of California Santa Barbara orientations, and community conferences to make positive changes in our community.
KEYWORDS

youth, leadership, social action, Isla Vista, awareness, Latino/a

I N T R O U C T I N - W H O W A R E Two years ago when we started our campaign, the University of California Santa Barbara (UCSB) was listed in the top three "party schools" in the country (CBS Broadcasting Inc., 2014). The town where we live, Isla Vista, is next to UCSB and is considered a college party town. Isla Vista is located in the Central Coast of California and is an unincorporated area of 23,000 residents in less than two square miles. Because we don't have the same rights as an incorporated town, it often feels like when our town makes the news for something good, Santa Barbara takes credit; however, if headlines are bad, no one wants to take responsibility. However, Isla Vista is much more than an "unincorporated area" or a "party town": It is also a place where kids grow up. Many 
of the Latino/a $\mathrm{a}^{1}$ families have been here for multiple generations, and yet some have been kicked out of Isla Vista to make room for college students.

\section{S Isla Vista is much more than an "unincorporated area" or a "party town": It is also a place where kids grow up.}

Although the current racial diversity of Isla Vista is similar to UCSB (Isla Vista is 53\% White, 23\% Latino/a, and 17\% Asian), the majority of families here are Latino/a. The college students also tend to come from wealthier backgrounds. The median family income of UCSB students is over $\$ 100,000$, and the university has more students from the top $1 \%$ compared to other colleges in California or highly selective public colleges across

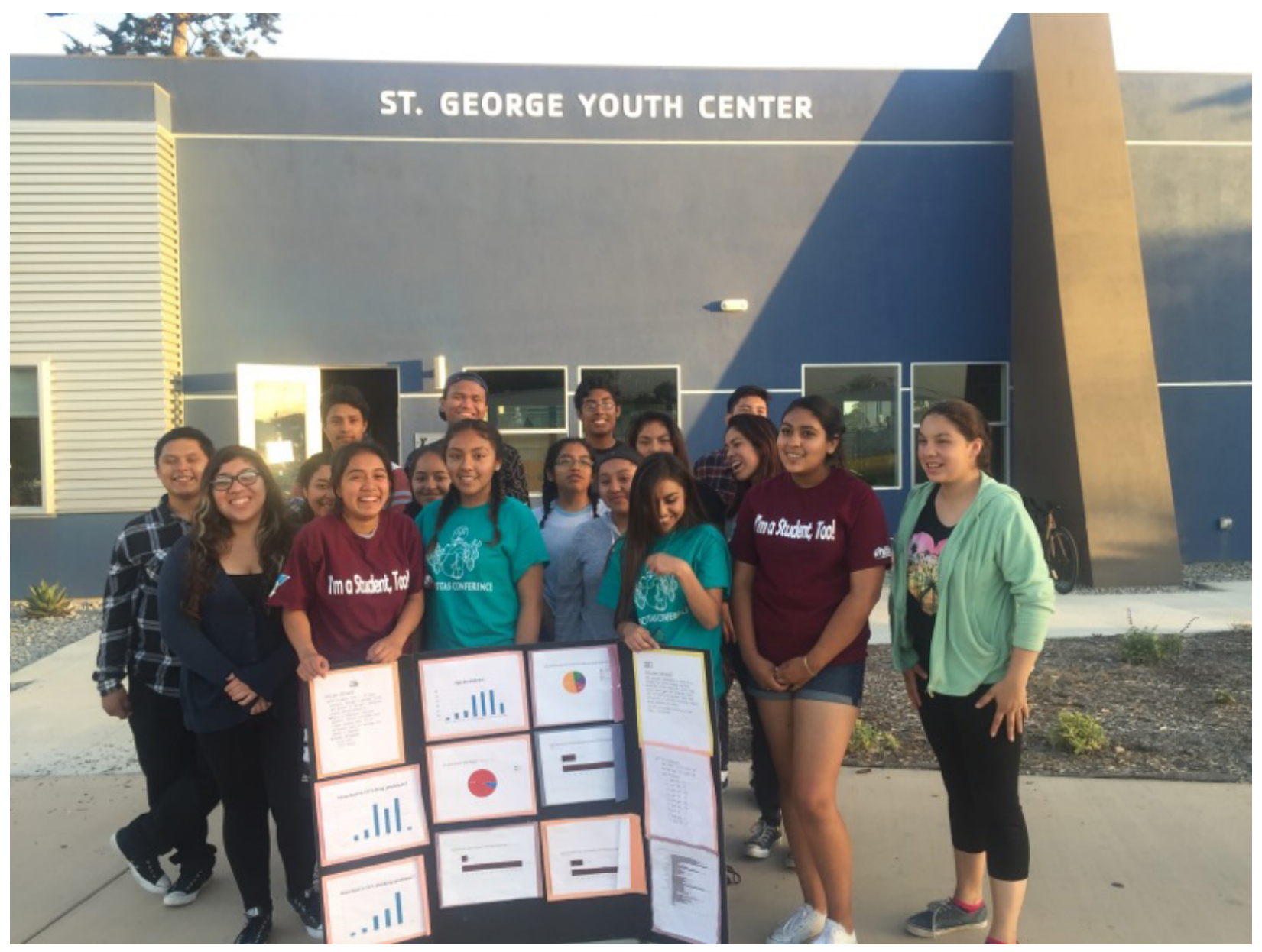

Figure 1. St. George Youth Center Leadership Group after the first community town hall meeting.
1. We decided to use the term "Latino/a" after a few discussions with our youth leadership group. In general, we find the term "Latinx" foreign and feel more comfortable using the word "Latino/a" to describe ourselves and our community. We appreciate how the term "Latinx" is inclusive since it is gender neutral, but part of our discussion was about appreciating the Spanish language and culture considering our current project about renaming streets. Therefore, we refer to people in our leadership group and broader community throughout the article as "Latino/a." 
the United States (New York Times, 2017). In comparison, the average Latino/a family living here makes around \$20,000 and Latino/a residents come from all walks of life-from newborns to people over 80 years old. The difference in the number of families versus number of college students (and the reputation of Isla Vista) means that many UCSB students don't know that a quarter of residents are families. Before our campaign, they were even less likely to know about the Latino/a teens in our leadership group working to make a difference.

We are part of the St. George Youth Center's Isla Vista Teen Leadership Group. The whole group is made up of 16 members aged 13-18, all with different positions such as President, Outreach Chair, and Events Chair. We also collaborate with the St. George staff and UCSB researchers as a universitycommunity partnership. We work towards creating a better, safer, and healthier place where youth and families can grow up. We do this by improving our teen center, putting on community events and festivals, and learning more about our town and environment. Our goals are to reduce alcohol and other drug abuse in Isla Vista - a big issue with college students - but one that also affects families here. In general, we raise awareness of the diversity of students living and growing up in Isla Vista, from kindergarten through college. We care because we live in

We care because we live in this community and because sometimes people, including other community members, overlook the needs of the children and their families who live here as well. this community and because sometimes people, including other community members, overlook the needs of the children and their families who live here as well.

Therefore, in our article, we talk about how we created and carried out the "I'm a Student, Too!" campaign and what it continues to mean to us and our community. We describe how we surveyed hundreds of people to collect and present data about sound levels to document noise issues. We also write about creating a community mural, and our experiences in public speaking to raise awareness about our group and its aims. Finally, we report what we learned from our projects, the significance of our work, and we offer advice for other youth leadership groups.

C A M PAIG N In the past few years, we've been working on a project called "I'm a Student, Too!" The project goals consist of informing community members in Isla Vista that there are families living here. The main reason we began this campaign was because during a workshop discussion about living in Isla Vista, we realized that there were things we wished we could change. 
Ultimately, we decided to do something about it. The issues we discussed included how the college students from UCSB and SBCC (Santa Barbara City College) have a reputation for having parties with loud music and drinking in public, among other things, regardless of whether or not they know of the families and youth that live next door. According to the UCSB student paper The Daily Nexus, "While substance abuse issues face college students nationwide, many health professionals are claiming UCSB students face concerning academic and social pressures that have led to drug and alcohol use, statistics that largely exceed that of the national average" (Quiambao \& Peng, 2013, p. 1).

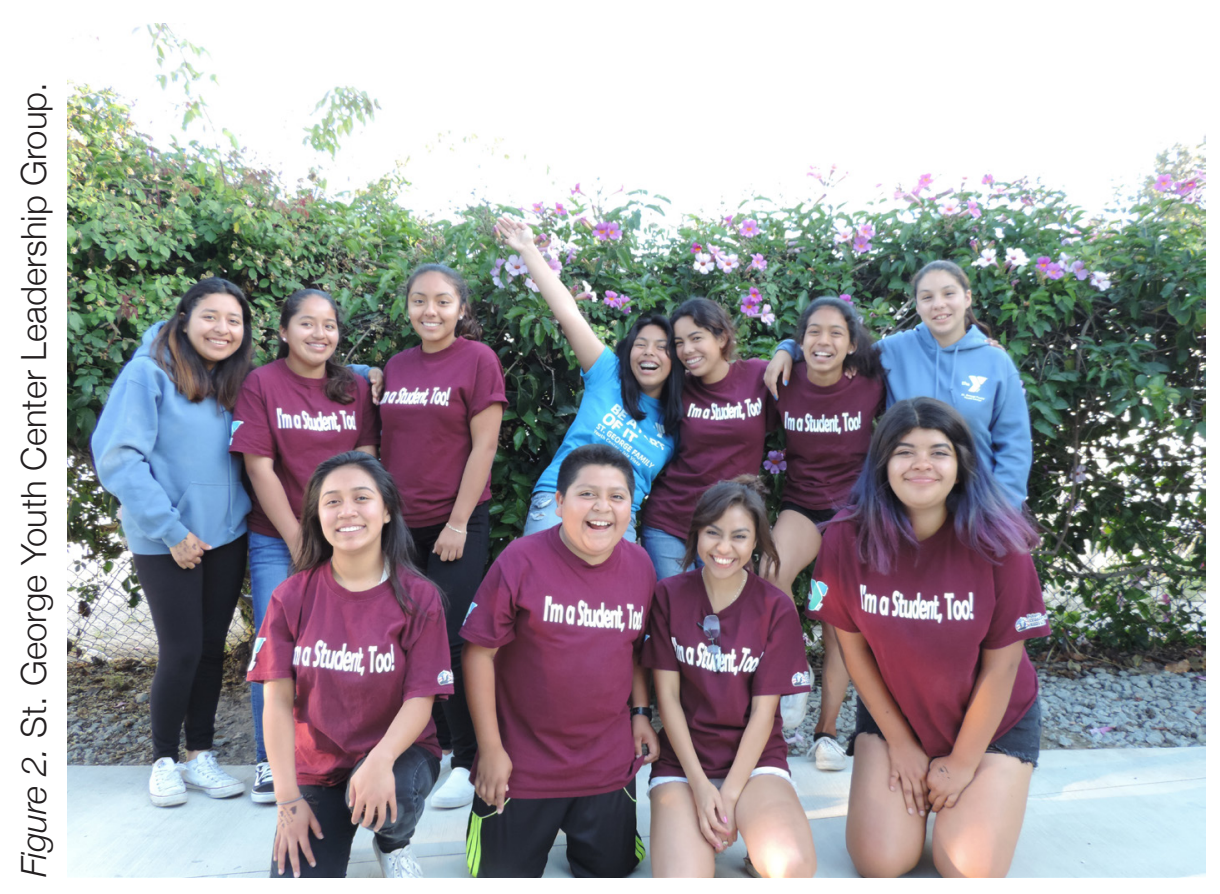

Youth in our group have personal experience with these issues. In our discussions, Odalis told stories about her parents having trouble sleeping at 2 a.m. due to loud music on weekends, yet still needing to get up for work early in the morning. Maria talked about college students offering kids drugs when they went trick-or-treating on Halloween, and Nicole mentioned seeing drunk people passed out on her front lawn in the morning. Kelly and Ashley, like many of us, don't feel comfortable going to the beaches or parks nearby when students are there drinking. We also talked about volunteering and helping pick up trash after the big street festivals each year because the partiers leave behind lots of litter. All of these issues led us to start our research and social action project, "I'm a Student, Too!"

The Isla Vista community tends to focus on UCSB students and can forget about the needs of the families and students that aren't in college but share the same town. The title 
says it all: we are students, too. Odalis, a 15 year-old member who was born and raised here says, "My week consists of 62 hour work loads. Some of my nights at home in Isla Vista while I'm doing homework, it can get pretty loud outside. This is my community, too. I'm a student, too." She has the same amount of work, attends school for more days a week than most college students, yet she has to deal with outside influences that are distracting from her success. Even though we are younger than the university students, we are all striving to do better and become educated.

Our families and children want a safe and friendly community in which to grow up, and are working to make Isla Vista a positive place. We believe that issues of noise and fireworks, public drinking and smoking, littering, and reckless driving can be fixed if we all remember to respect our fellow neighbours. University students who know about the families in Isla Vista tend to understand, but unfortunately most people are not aware that Isla Vista is more than a college town. To raise awareness of these issues and make a difference, we started our campaign.

\section{Phase 1-Creating the Campaign and Surveying}

For our "I'm a Student, Too!" campaign, we partnered with Future Leaders of America, a youth empowerment group in the Santa Barbara community. We had our first meeting in December 2015 where we discussed starting a campaign and addressing a problem, and what we could do to fix the problem. We discussed how this is our home as well and since there are issues impacting us on a daily basis, we should have the ability to change them and create a safer and better environment. In Phase 1, we created a survey and asked 200 residents (ages 5-64) what they thought about issues in our town. We received a lot of negative comments, with people scared and upset about alcohol, drugs, noise, and safety. After receiving the results and interpreting them, we decided we needed to do something to draw attention to these issues and create ways to improve them. We also didn't just want to create a negative view of our home, so created a new survey to ask about the positive side of Isla Vista. According to Bonfilia, a 15-year-old member, "We wanted to show that, yes, there are some concerning things about living in Isla Vista, but it's also a wonderful place with some beautiful qualities" (Sen, 2017, p. 62). This led to the creation of our \#BestOflslaVista video (St. George Youth Center, 2016). People held up posters with drawings or key words showcasing the reasons why they liked living in our community. We also created a positive word cloud using keywords from the posters of people's favorite things about Isla Vista. After that we compiled our data and presented at town halls, university classes and orientation, and two 
community conferences held at the St. George Youth Center in Isla Vista.
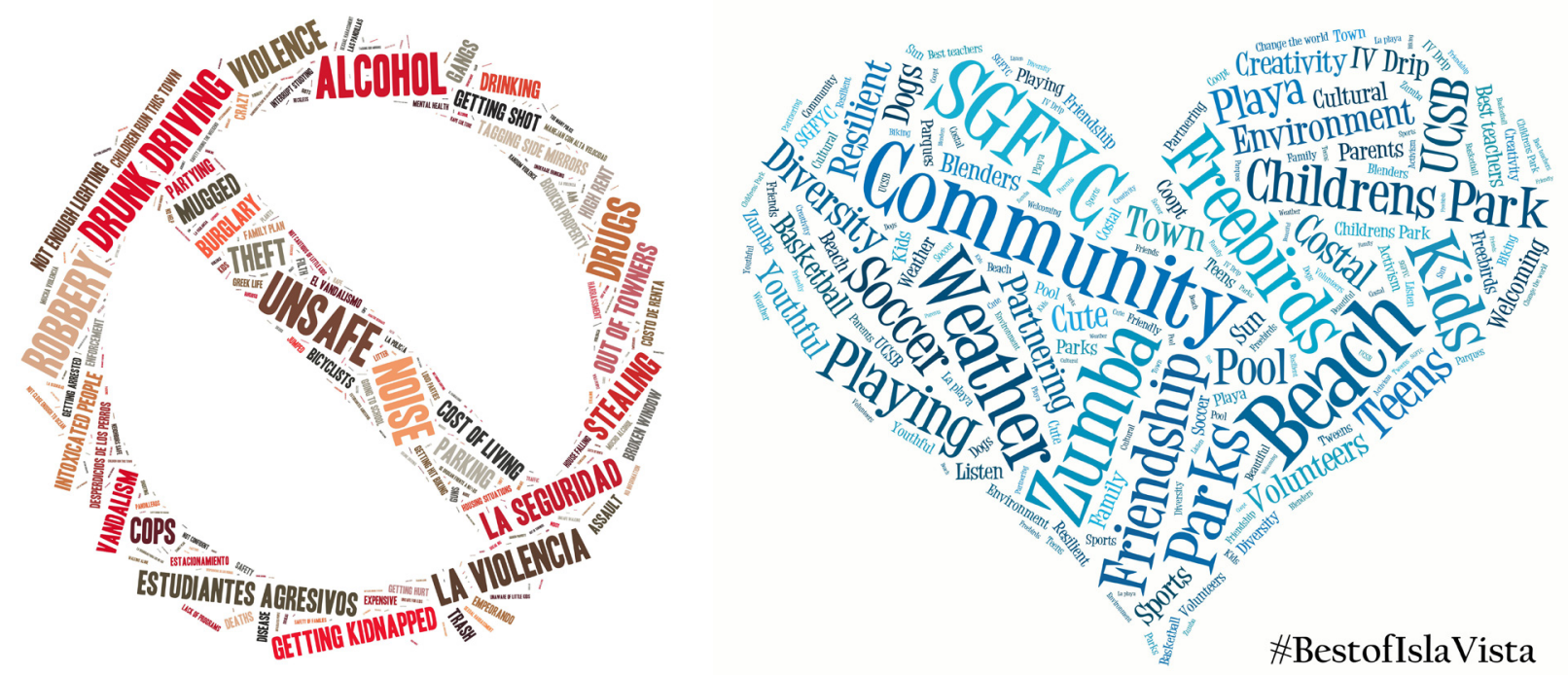

Figure 3. Negative and positive word clouds based on surveys of residents of Isla Vista.

\section{Phase 2a-School Surveys}

After Phase 1, we wanted to get the word out about our campaign. We designed and wore t-shirts that showed the positive word cloud and our campaign name. When many of us were asked, we explained the campaign to students at our school who weren't from our town. We received a lot of other teens' thoughts about Isla Vista. Some were positive, some were negative. From this, we decided to ask their opinions, and surveyed 700 students from local junior and high schools in the Santa Barbara area. Of our surveys, $70 \%$ were given to high schools and $30 \%$ to junior high schools. Almost $8 \%$ of the total students surveyed lived in Isla Vista. For the students surveyed, we asked:

- How many times have you visited Isla Vista, and where did you go?

- Do you know there are families living in Isla Vista?

- Have you ever had any alcoholic beverages in Isla Vista? How many drinks did you have?

- What words would you use to describe Isla Vista?

- Have you used any drugs in Isla Vista?

- Do you live in Isla Vista?

- Have you heard of the "I'm a Student, Too!" campaign?

- Have you seen the new advertisement on TV?

These questions helped us gauge what other teens knew and thought about Isla Vista. We also wanted to know more about the alcohol and drug problem and how it affected teens. We asked if people knew about our campaign and the advertisement, to see how far our message had spread from Phase 1, and to raise awareness that not only college students 
live here. We found that some of our classmates didn't know about the families that live in Isla Vista, and amongst those who were aware, they still had the perception that it was a party town. According to our survey results, the party town reputation did not seem accurate, at least for most teens visiting Isla Vista. Over $90 \%$ of the junior and high school students responded that they hadn't had drugs or alcohol in Isla Vista. However, of the $10 \%$ that did drink in Isla Vista, they had consumed four or more drinks at one time. As for drug usage, marijuana was the top drug of choice, with tobacco and prescription drugs in second place. We found it interesting that most non-resident teens thought substance abuse in Isla Vista was much more of an issue than the reality of what actually occurs. Furthermore, while most teens did not engage in drinking or drug use in Isla Vista, the ones that did had really bad substance abuse habits that we hoped to address later.

Non-residents of Isla Vista tended to view Isla Vista as a neutrally safe to slightly unsafe place, while on average residents felt safe to extremely safe. We also learned that the majority of people hadn't seen the ads or heard about the campaign. The results from the surveys were very important to our campaign because the goal of our surveys was to see people's perceptions - specifically high school and junior high students' - of Isla Vista. Using this data, we hope to work with our surrounding communities to make sure we showcase the best of Isla Vista, while also acknowledging issues we can improve upon.

\section{Phase 2b-Sound Project}

After the Phase 1 survey and data analysis showed us that noise was one of the biggest issues, we decided we needed to know more. Since there was no data available on sound levels in Isla Vista, we decided to be community scientists and collect our own data. We were trying to prove the claim that Isla Vista is too loud, and then do something about it. We recorded data throughout Isla Vista to help support our claims of when and where it was loud. We collected data by using our phones to record decibel levels around Isla Vista. We installed decibel apps on our phones and practiced, came up with guidelines for individual recordings, and had group recording days (See Figure 4). We also learned about the behavior of sound waves and how they related to high and low frequencies and amplitudes.

Our data analysis team sorted the collected data by day of the week and calculated maximums, minimums, and averages. They also created graphs and visuals. The quietest sounds ranged from 27-50 decibels, which included birds, ambient noise, frogs, and bikes. Around 40 decibels are normal for a quiet neighborhood, so we had evidence that Isla Vista can be a quiet 

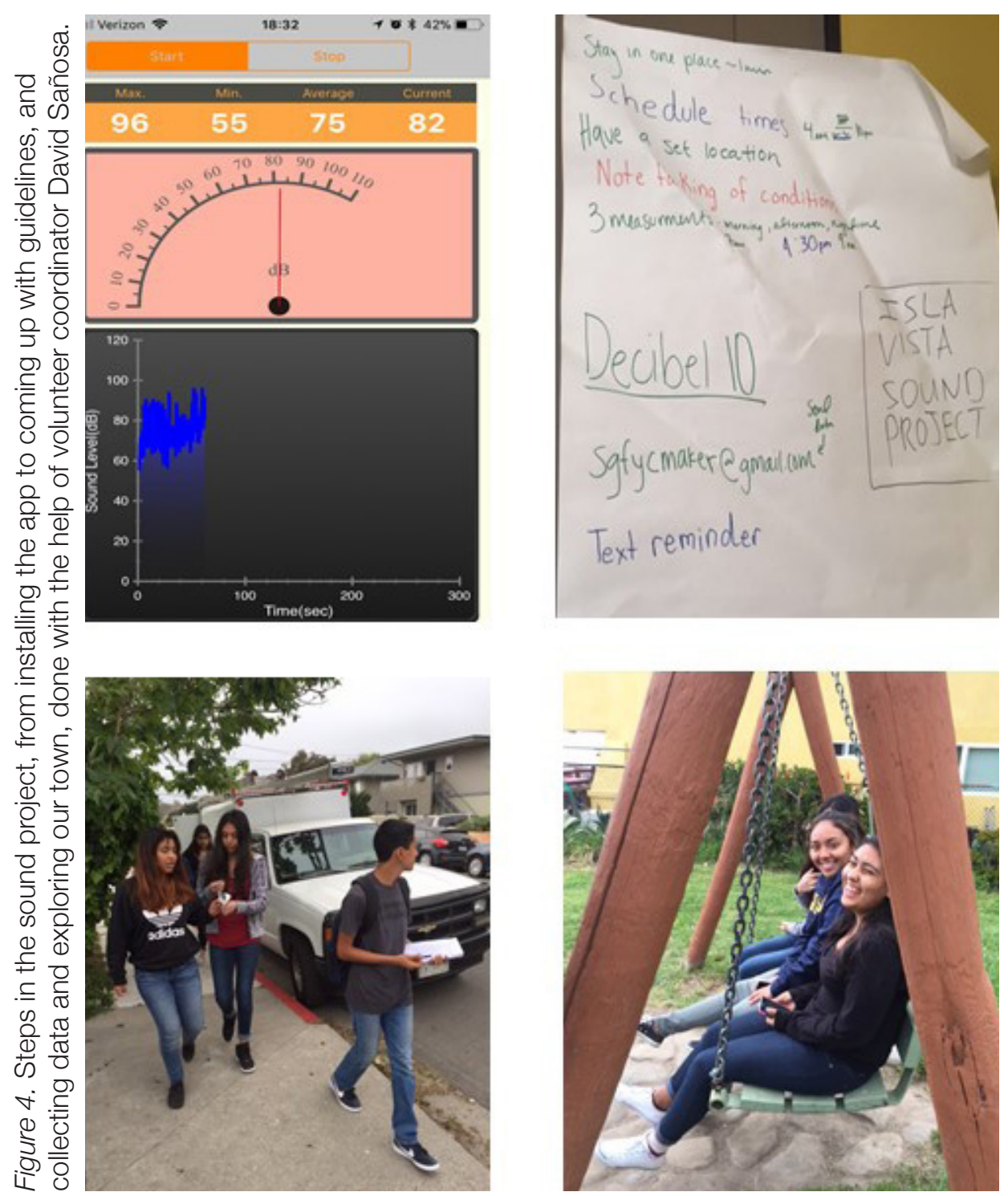

place. The loudest sounds were 99-108 decibels, which included wind, traffic, parties, and music. A power lawn mower produces a sound at a decibel level of 100, and one-time exposure to 100 decibels can cause serious ear damage (Dangerous Decibels, 2018). The quietest day of the week was Monday with an average of 80 decibels; the loudest day was Thursday at 91 decibels (See Figure 5). Long-time exposure to sounds at 85 decibels or more can cause hearing loss (Dangerous Decibels, 2018). The average decibel levels for Thursday through Saturday were very loud, and we talked about noise pollution and what that means for the people who live here. Long-term, large amounts of noise cause more conflict between families and college students, and is bad for everyone's health.

Finally, we made graphs to show sound levels and created a map of Isla Vista, illustrating the sounds of different areas such as music, children at the park, and restaurants. We presented our graphs and map at a town hall, explaining that families just want a quiet neighborhood for their children. There have been 
many claims about noise concerns in the past, however no one has taken the initiative to record and share data.

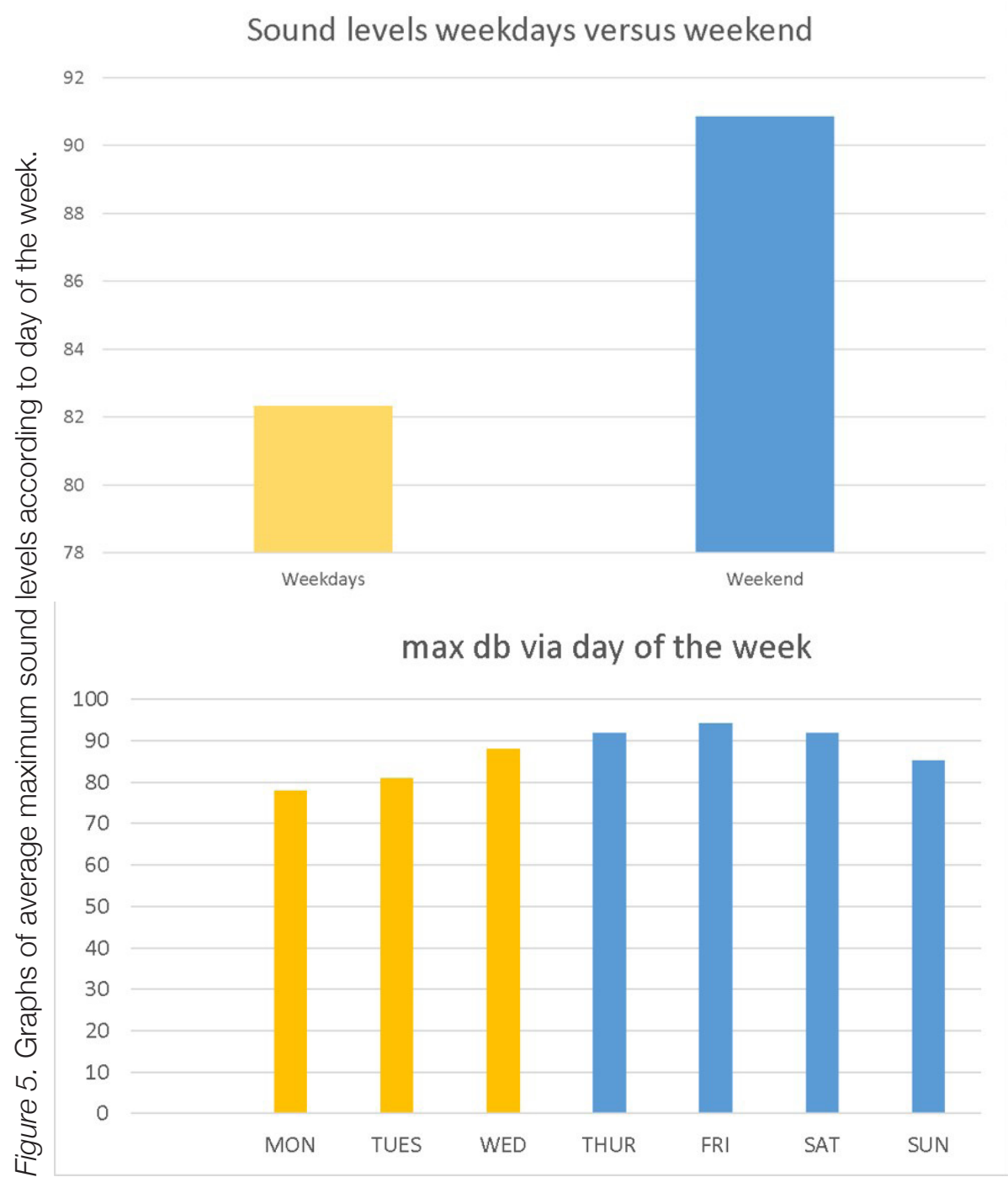

We learned that we should have a larger sample next time for our data to be more representative of Isla Vista. We needed to collect more data, especially in the evenings since we didn't have any recordings after 10 p.m. Next time we plan to avoid a cluster sample because it is unreliable. We learned that for a cluster sample, researchers sample only a specific area, and the results are biased because they are not representative of the whole area. Instead we should do a stratified sample. In the future we will divide Isla Vista into equal squares, to get more data points and figure out the average. This is important to eliminate as much bias as possible to ensure a reliable and credible array of data to support our claim. Beyond collecting more data, we are also still attending community meetings, where they are talking about a noise ordinance and limiting loud music late at night. 


\section{Phase 3-Mural Project}

After the surveys and sound project, we decided to get the word out through art. We met with a local artist and looked at photos of Chicano/a murals for inspiration. We searched through public artwork and designs, and in the process we learned that every mural has a story to tell. We had a brainstorming session for our mural. We talked about what Isla Vista means, and if we should use images of the beach, people, culture, or music. We used it all. We considered adding phrases such as "quisieron enterrarnos, pero no sabían que éramos semillas", or "they tried to bury us, but they didn't know we were seeds". Even though we still feel strongly about the meaning behind the quote, it would have been too long to fit on the mural.

For our final design, in the front and center of the mural, we put a young woman of color to honour the female youth

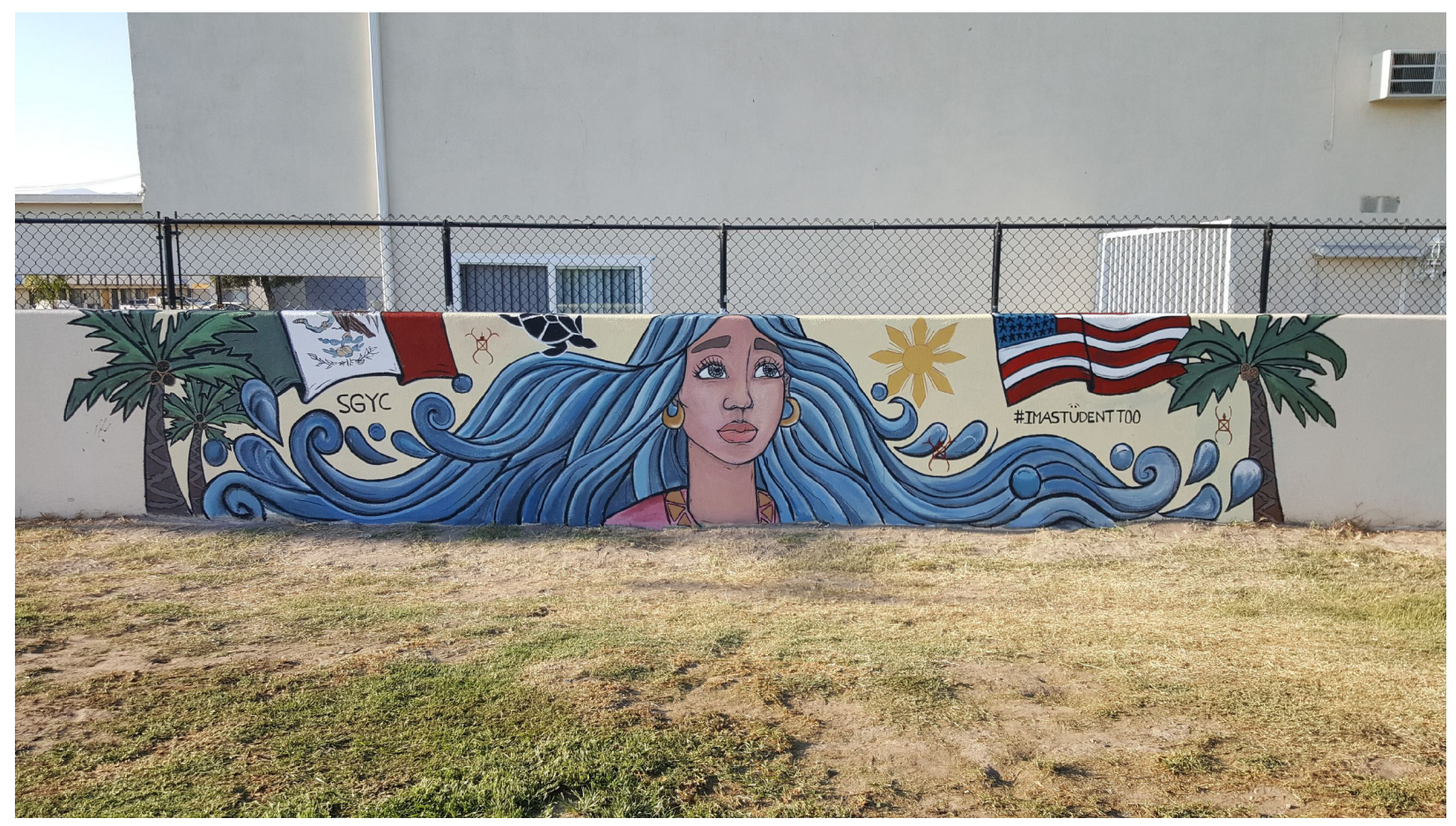

Figure 6. Mural next to the St. George Youth Center that we designed and that was painted by Isla Vista youth, artist Gabriel Cardenas, and volunteer coordinator Stephanie Arguera. leadership of the last year and their contributions. Her hair is waves because the ocean is a part of us all - undeniably beautiful. She looks up and forward, looking to the future and to the elders who watch over everyone. We chose palm trees to represent the paradise of Isla Vista and its long history. Around the woman, we added Mexican and American flags. However, we wanted to make it clear that there are other groups and cultures here. We wanted to show unity. We added the Filipino star, Chumash turtle, and the Shiva from the Hmong flag to represent these communities as well. The Chumash turtle honors the Indigenous people currently living all over Turtle Island, or 
North America. The turtle also represents the ancestors of this place, the on-going Chumash traditions, and that we are all tied to the Earth. The Shiva is the Supreme being of the Buddhist tradition who creates, protects, and transforms the universe.

To receive approval, we talked to officials and presented the idea at the Isla Vista Parks and Recreation Department board meeting. We presented a sketch of the mural, and talked about our ideas. They asked us questions and then approved it. We worked with the artist Gabriel Cardenas who painted other murals in Isla Vista, and he told us, step by step, what to do. First, we sketched onto the wall. For some parts of the mural, we created the designs, such as for the trees, while the artist sketched out the portrait of the woman in the center. He was experienced and sectioned off the portrait into squares and gave us things to do. We painted the background trees, ocean, and symbols while the artist did the detailed work and roughed out the edges. It went by quickly; we put in five days of work, for 30 total hours, with 20 people helping.

At the end, we had a ribbon cutting ceremony. We received many positive responses from the park visitors. Many people walking by stopped to take photos and talk about the mural. One woman's comment really stood out. She came up to us and said, "Thank you for doing this, we really need this right now," referencing the current political climate and how people are on edge over our current president's election and racist rhetoric. While our intentions are not political, they are unifying and promoting the diversity of Isla Vista. The mural represents minorities everywhere, including Isla Vista. The mural includes the "I'm a Student, Too!" hashtag and was an important contribution to our campaign. It gives more visibility to families and youth of color who are also students, but who are often forgotten by the university student population.

\section{GETTING THE WORD OUT AND FEEDBACK}

Besides the mural and ribbon cutting ceremony, we held two town halls at the St. George Youth Center and presented to the community. In general, people were very positive. However, there was a negative reaction to the newspaper article written about our first town hall. Unfortunately, the article was called "Teens Express Frustrations of Living in Isla Vista", which made it seem like we were angry about the college students and didn't want them there (Bogel-Burroughs, 2016). It caused a lot of controversy and people argued with each other online in hate-filled comments about the article. Some asserted that trying to change Isla Vista was hopeless, that Isla Vista was, and always would be, a party city. We had encountered similar 
views throughout our campaign. We were surprised that people didn't understand our findings and thought of our calls for action as "frustrations," and didn't believe change was possible for our town.

We decided to write our side of the story and published an article in the UCSB magazine Word (Sen, 2017). We did this because our mission is not to demonize other people but to express our problems. We saw something happening and decided to take charge. We also put on another community town hall, and ended it by asking questions to create more productive conversations between college students, teens, families, and other residents in our town. We asked:

- How do we engage our community partners and college students in real dialogue and accountability?

- How do we create a separate identity for Isla Vista, as a beautiful, small beach town with a vibrant and diverse community?

- Do the rights of the masses (to party, to have the "college experience") supersede the basic human rights of the minority? (The right to a safer and healthier Isla Vista.)

- How do we continue to make others aware that there are kids growing up in Isla Vista that are also students? From kindergarten through high school, these kids need a nurturing environment to learn, grow and make it to college themselves.

We discussed many options to bring our community together. Some people felt that we needed to do more outreach

Although we don't have the answers to all of these big questions, we were happy to start conversations between different people and we hope to keep the dialogue going. and engage more with our community partners, while others felt that we should have more events that include all residents: families, kids, college students, etc. Almost everyone felt that that the rights of the masses do not supersede the basic human rights of the minority because exercising rights goes only so far and should not infringe on others' rights. One person even stated, "Majority status doesn't allow abuse of rights." Although we don't have the answers to all of these big questions, we were happy to start conversations between different people and we hope to keep the dialogue going.

Finally, we presented at a countywide Youth Conference called "Take the Lead" and showed our \#BestoflslaVista video for Gaucho FYI, a required workshop for freshmen at UCSB. Our video's addition into Gaucho FYl further cements the diverse population as well as the presence of youth and families in Isla 
Vista. It gives a clear message to new and incoming UCSB students that our community is not solely a college town, and that we need to be aware of and respectful towards all of our community members. We have made progress in presenting a few times, but we want to have a permanent place in the orientation schedule. We are still working on creating more permanent spaces in Isla Vista and UCSB, where we can share our stories as well as raise awareness of youth and families in Isla Vista and our "I'm a Student, Too!" campaign. However, the word cloud, our \#BestoflslaVista youtube video, and our mural are all permanent fixtures of our Isla Vista Community.

\section{LESSONS LEARNED}

We have spoken at town hall community meetings and conferences, and created shirts, word clouds, and a mural. During the project we met new people, learned leadership skills, and gained an awareness about local issues. Almost everyone felt they learned something from the project, and people grew in different ways. In general, we learned to build relationships and improve teamwork and communication to further our leadership goals. Many of us are now more confident speaking in public. People learned to be more social and coordinate with others who don't necessarily come from the same background or understand our goals. Others learned to be more aware of their surroundings or to look for problem solving solutions. Finally, one of the most important lessons learned was the power of collaboration. When working with Future Leaders of America (another youth group focused on politics and social change), they helped us find what we truly wanted to achieve. They had previously run campaigns themselves and collaborated with us to ensure our success.

We are happy to say that the nearby university is no longer on the top ten party list (Day, 2017), which gave a bad name to our community. While some people celebrate having their school on the party list, we see the list as something that raises awareness about an issue. For other towns that have universities on the party list, we want them to know that they're not invisible and they can make a change. Making the university aware of their presence is possible, so they shouldn't be afraid. They should use the party list status to motivate them, and express themselves as part of the broader community. We're not trying to antagonize party colleges, but they do influence the people around them. We are writing about this to recognize that we have done a lot, learned even more, and hopefully made an impact. We also realize that there are many places in the world that have worse issues than here, but it's important for us to do what we can, to inspire other generations to take charge. 
NEXT STEPS Many of us feel that despite all our work, we still have a long way to go in making Isla Vista a better place for Latino/a families and children. We plan to continue to get the word out about our campaign. We want to bring back our roots by re-establishing that we are students, too! We want to continue to make college students aware that there are youth and families living in Isla Vista, reduce drug and alcohol consumption, create a better place for children to grow up, and keep community members informed.

We are starting our next project, named "Project Ñ." Our ambitious project attempts to change the street names in Isla Vista for equality, and ethnic and linguistic awareness. For example, changing the street named Sueno to Sueño. The reason why it's called "Project N" goes, however, beyond Sueno Road. The "ñ" is a commonly used letter that doesn't exist in the English alphabet, and adding the tilde creates a different pronunciation that comes with a lot of history.

Before starting the project, we read articles from old newspapers about the origins of Santa Barbara and Isla Vista. We learned about the Chumash Indigenous people who live here, the old ranches (two of which have the namesakes of Dos

By changing street names now, we're Pueblos High School and By San Marcos High School), not trying to use the correct Spanish to and who named our town Isla emphasize the grammar, but to value the Vista. Two people from out of people who live here and our heritage. town purchased the land and named the town "Isla Vista"

instead of "Vista de la Isla" and also invented the grammatically incorrect streets Del Playa, Sabado Tarde, and Sueno. We're not sure why they used Spanish, but it could be for tourism since they divided up the area for rentals. By changing street names now, we're not trying to use the correct Spanish to emphasize the grammar, but to value the people who live here and our heritage. For example, Del Playa is the name of one of the most famous streets in Isla Vista. Changing the name to De la Playa would also make people more aware of Latino/a influence on the past and current history of Isla Vista. We're correcting the grammar to represent the idea that all people should be respected, and as a symbol for others to seek change. 


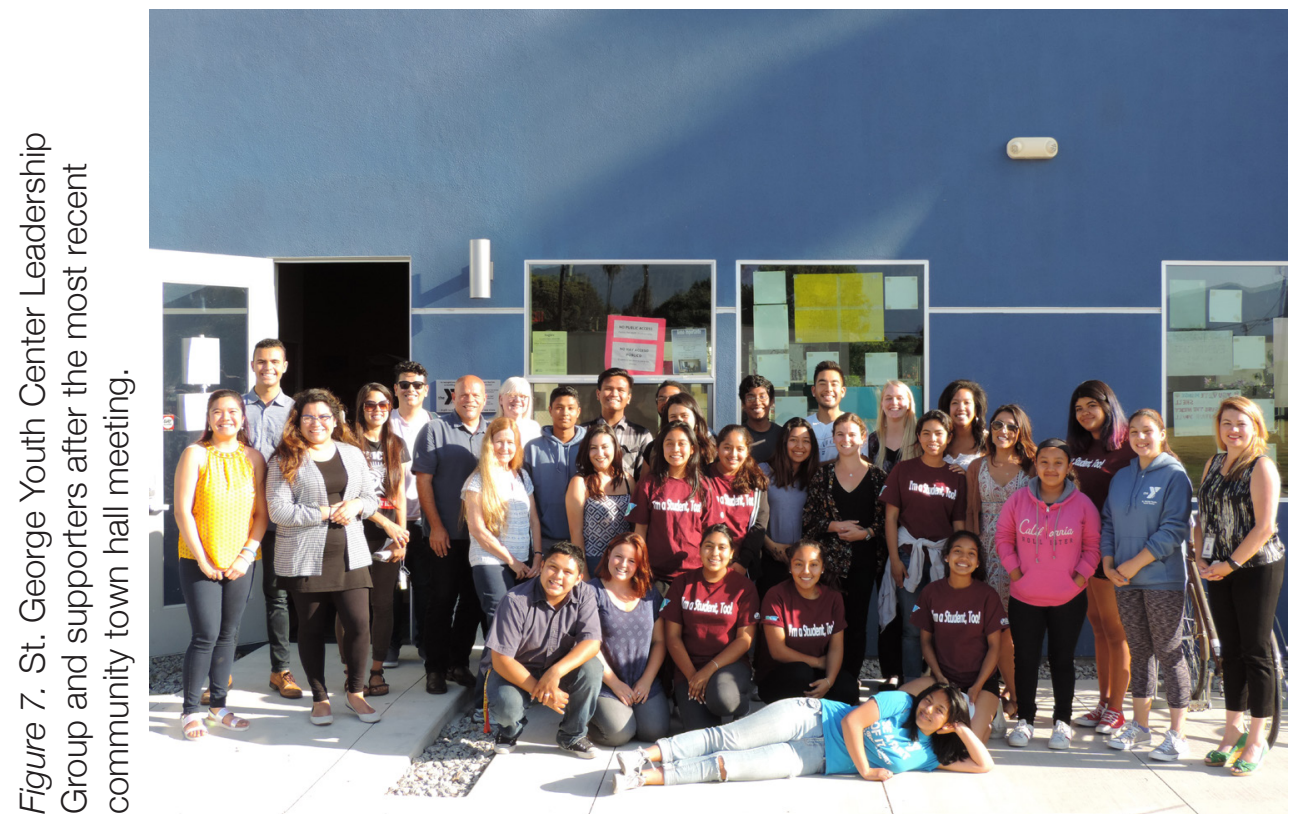

CONCLUS ION

In general, we continue to improve our community through events and new campaigns. Although we are still learning, we hope other youth groups will read about our work and create change in their communities. For other leadership groups, we recommend that they learn more about their surroundings and resources, so they can help themselves while also helping their community. We advise them to have clear communication, share ideas, and get people in the community involved. It is also powerful to do their own research such as create, collect, and analyze survey responses. Finally, it is important to work together, and have fun in the process!

We want to tell other youth leaders that nothing should stop them. If they see a problem they don't like in their community, there are probably a lot of people who feel the same way. They should get together and work on changing it. They should never underestimate the power that they have - the power of youth. Because even the smallest change has an effect, and that's how the world evolves.

\section{A C K N OW LED G E M EN T S}

Thank you to the St. George Youth Center's Isla Vista Teen Leadership Boards of 2016-2017 and 2017-2018, as well as IVTL as a whole. Without your hard work, time, effort and, most important, the love you all have for Isla Vista, this campaign would not be what it is today. A big thanks to the Future Leaders of America for collaborating with us in our campaign, as well as supporting us in our efforts to create positive change in our community by helping us raise awareness about youth and families living in Isla Vista. Last, we would like to thank Leonor 
Reyes, SGYC's Program Director, for her endless support, crucial feedback, and essential role at the Youth Center and in our Isla Vista community.

Bogel-Burroughs, N. (2016, April 28). Teens express

R E F ER E N C E S frustrations of living in Isla Vista. The Daily Nexus. Retrieved from http://dailynexus.com/2016-04-28/teensexpress-frustrations-of-living-in-isla-vista/

CBS Broadcasting Inc. (2014, August 14). Princeton Review ranks UCSB No. 3 for top party schools. CBS LoS Angeles. Retrieved from http://losangeles.cbslocal. com/2014/08/04/princeton-review-ranks-ucsb-no-3-fortop-party-schools/

Dangerous Decibels. (2018). Noise-induced hearing loss. Dangerous Decibels, University of Northern Colorado. Retrieved from http://dangerousdecibels.org/education/ information-center/noise-induced-hearing-loss/

Day, C. (2017, July). UCSB no longer top ten party school in The Princeton Review. The Tab: UCSB. Retrieved from https://thetab.com/us/ucsb/2017/08/01/ucsb-princetonreview-3442

New York Times. (2017, January). Economic diversity and student outcomes at the University of California, Santa Barbara. Retrieved from https://www.nytimes.com/ interactive/projects/college-mobility/university-of-californiasanta-barbara

Quiambao, C., and Peng, R. (2013, May). Substance abuse: Perceptions and reality. The Daily Nexus. Retrieved from http://dailynexus.com/2013-05-22/substance-abuseperceptions-and-reality/

Sen, F. (2017, January). I'm a student too: Isla Vista teens research the landscape. Word Magazine, 30, 60-63.

St. George Youth Center. (2016, July 1). Best of Isla Vista. [Video file]. Retrieved fromhttps://www.youtube.com/ watch?v=711jVPv0la4 